\title{
Revista Médica Vozandes: 32 años generando evidencia científica
}

\author{
Katherine Rosero ${ }^{1}$, Santiago Rodriguez ${ }^{2}$
}

\section{OPEN ACCESS}

Este artículo está bajo una licencia de Creative Commons de tipo Reconocimien- No comercial - Sin obras to - No comercial - Sin obras
derivadas 4.0 International.

1. Médico Tratante Medicina Familiar - Hospital Vozandes Quito. Tutora Posgrado Medicina Familiar Pontificia Universidad Católica del Ecuador. 2. Médico Tratante Hepatologia - Hospital Vozandes Quito.

\section{ORCID ID:}

Katherine Rosero

Santiago Rodríguez

http:/ / orcid.org/0000-0001-8610-3622

Correspondencia: Dra. Katherine Rosero

E-mail: krosero@hospitalvozandes.com https:/ / orcid.org/0000-0001-6856-9074

Las revistas biomédicas desde sus inicios en el siglo XVII han sido y continúan siendo la fuente más importante de comunicación científica y actualmente representan el principal canal de comunicación y educación continua para los profesionales de la salud. ${ }^{(1,2)}$

La aplicación del método científico dio origen a una actividad creciente y fructífera: la investigación, la cual permitió establecer las bases de la ciencia moderna.

Los diferentes autores encontraron en las revistas biomédicas el campo ideal para contrastar opiniones, difundir sus resultados y generar evidencia, acciones necesarias e importantes para el investigador como para la comunidad científica y la sociedad como un todo. ${ }^{(1,2)}$

Con el perfeccionamiento de diferentes sistemas informáticos y de comunicación, difundir el conocimiento cientííco y obtener datos estadísticos de relevancia clínica, son ahora más fáciles; pero a la vez se convirtió en un gran desafío. ¿ Cómo verificamos la calidad de la información? ${ }^{(3,4)}$

Actualmente, las publicaciones de las ciencias de la salud cuentan con mecanismos internos de control de calidad para seleccionar y publicar manuscritos relevantes. ${ }^{(1,5)}$

Forma de citar este artículo:

Rosero K, Rodríguez S. Revista Médica

Vozandes: 32 años generando evidencia científica. Rev Med Vozandes. 2019;

30(2): $7-8$ Actualmente crear redes de investigadores es una estrategia básica
Históricamente, el Hospital Vozandes se ha caracterizado por promocionar y difundir conocimientos de interés científico en el ámbito de la salud local, por esta razón y con el objetivo de incentivar la investigación biomédica, en el año de 1987 se publica el primer volumen de la Revista Médica Vozandes (dos manuscritos originales, dos revisiones clínicas y un reporte de caso), orientada bajo pilares fundamentales: docencia y conocimiento científico.

En 1991, la Federación Médica Nacional categorizó al Hospital Vozandes como Hospital Docente: reconocimiento tácito a su labor académica a través de los años, esta distinción fue plasmada en el editorial del volumen 5 donde queda evidente la prioridad máxima del hospital en la formación de profesionales que cumplan con las necesidades y expectativas de la salud en el Ecuador.

En el volumen 12 (año 1998), se inaugura la sección cartas médicas, donde se abordan por primera vez temas como el glaucoma; y en el volumen 15, la Enfermedad del Fonendoscopio a cargo de la Dra. Susana Rodríguez, explica el profundo sentimiento por detrás de las palabras de nuestros pacientes; las verdaderas historias que se sienten al verlos como personas con necesidades que no para fortalecer el desarrollo de este campo, así como para la generación de información basada en evidencia la misma que permite mejorar los procesos de tomada de decisión y/o establecer perspectivas futuras, por esta razón desde 2014 Ecuador junto a España se ubican en el sexto lugar en el ranking de publicaciones conjuntas. (3) son solo biológicas sino psicológicas, emocionales, espirituales y sociales.

La periodicidad de la revista fue anual hasta el 2011 y a partir del 2012 hasta la actualidad es semestral. Entre los diferentes volúmenes, el 23, (12) representa la edición con mayor número de publicaciones: 24 entre los diferentes tipos de manuscritos.

La evolución se dio no solo en la periodicidad de la revista, sino tam- 


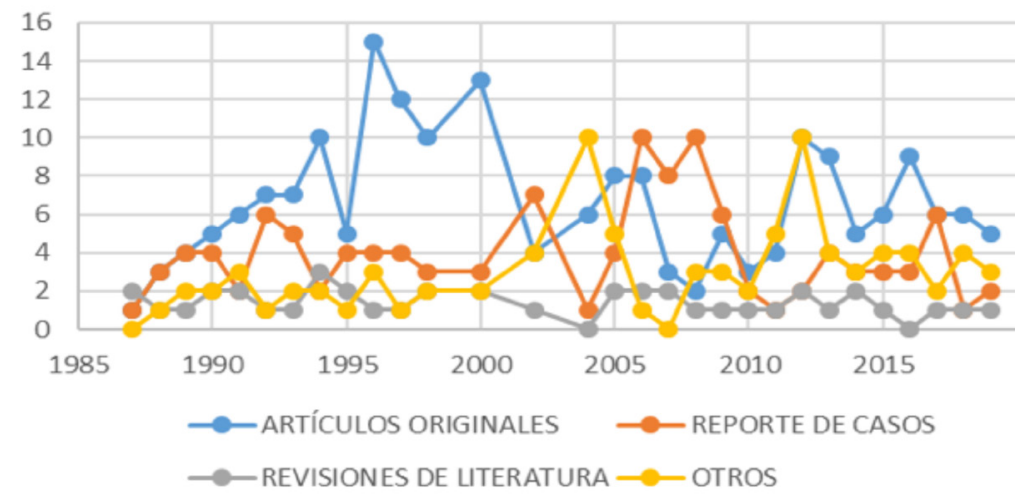

Gráfico 1. Tipos de manuscritos publicados en la Rev Med Vozandes desde su inicio en 1987 hasta la actualidad.

Realizada por Katherine Rosero

bién en las secciones, normativa, inclusión a base de datos internacionales, así como, en la adopción de estándares internacionales.

El volumen 14, año 2002 marca el crecimiento de la revista, se obtuvo el ISSN de la versión impresa bajo la coordinación del Dr. Antonio Naranjo y posteriormente la inclusión a la base de datos LILACS/BIREME en el volumen 19, año 2008 siendo editor en jefe el Dr. Galo Núñez de la Torre.

El volumen 23, año 2012, cuenta con el registro en la base LATINDEX (Sistema Regional de información en Línea para Revistas Científicas de América Latina, El Caribe, España y Portugal) e IMBIOMED (Índice Mexicano de Revistas Biomédicas Latinoamericanas), teniendo como editor en jefe al Dr. Juan Carlos Maldonado.

Los manuscritos publicados son elaborados bajo estándares técnicocientíficos siguiendo las orientaciones

\section{Gráfico 2. Diferentes portadas de la Revista Vozandes.}

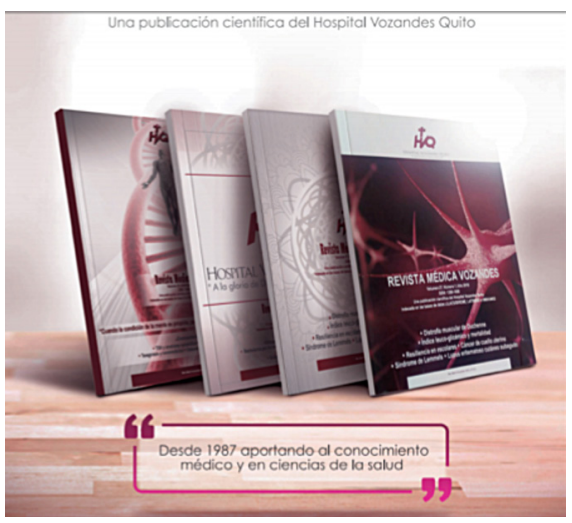

Realizada por Katherine Rosero del International Committee of Medical Journal Editors, de acuerdo al tipo y sección: editorial, manuscritos originales, reporte de casos, avances en medicina, imágenes médicas, cartas científicas, cartas al editor, práctica clínica, además de un estricto sistema de revisión por pares.

Durante esta trayectoria más del $40 \%$ de los manuscritos son originales, con un total de 439 en estos 32 años. (Gráfico 1).

Fotografías de la fachada del hospital, de la atención integral y social de las caravanas médicas Vozandes, así como imágenes alusivas a los manuscritos más relevantes publicados en cada volumen - desde dibujos originales con pincel electrónico hasta imágenes digitales - han marcado y acompañado el desenvolvimiento del diseño de la portada. (Gráfico 2)

El financiamiento se lo realiza con fondos institucionales propios y es de distribución gratuita. Hasta el año 2012 teníamos un tiraje de 1500 revistas (500 ejemplares eran distribuidos fuera de Quito por medio de la Universidad Técnica Particular de Loja, 500 se entregaban en las jornadas médicas organizadas por el hospital y 500 a las principales bibliotecas y hospitales de la ciudad). Actualmente, hacemos 500 ejemplares para las principales bibliotecas de la ciudad y hospitales. Además, la revista se entrega en formato PDF a todos los asistentes a las jornadas médicas, en promedio 300 participantes anualmente.

Una versión completamente digital, la inclusión de nuevas secciones como Dilemas Bioéticos, la obten- ción del Digital Object Identifier, así como la inclusión a bases más robustas, constituyen los retos de esta nueva fase, con el único objetivo que es: convertirnos en una revista referente en América Latina.

En definitiva, seguimos los paradigmas actuales de la divulgación y promoción de la información, mantenemos un acceso abierto, revolucionando la manera de acceder y comunicar el conocimiento científico.

La inclusión a bases de datos internacionales es un ejercicio de responsabilidad con los lectores y con los autores, que esperan que sus trabajos sean reconocidos en los más amplios ámbitos nacionales e internaciones de difusión, lograrlo no ha sido fruto de la casualidad, sino del buen hacer editorial, de su competencia y rigor.

\section{Referencias}

1. Pimlott N. What is a medical journal good for? Can Fam Physician. 2017 Sep;63(9):662.

2. Booth CC. Medical communication: the old and new. The development of medical journals in Britain. Br Med J (Clin Res Ed). $1982 \mathrm{Jul}$ 10;285(6335):105-8.

5. Densen P. Challenges and opportunities facing medical education. Trans Am Clin Climatol Assoc. $2011 ; 122: 48-58$

3. Belli S., Balta J., Virgili R. Ediciones Universidad de Salamanca - América Latina Hoy (2019). MAPEO DE LAS PUBLICACIONES CIENTÍFICAS ENTRE AMÉRICA LATINA, EL CARIBE Y LA UNIÓN EUROPEA Mapping of scientific publications between Latin America, the Caribbean, and the European Union. ISSN: 1130-2887 - e-ISSN: 2340-4396. Volumen 82, pp. 7-41. DOI: https:// doi.org/10.14201/alh201982741

4. Dorta M. Ciencias de la Información (2017). una experiencia de cómo publicar y difundir los resultados de investigación en acceso abierto. ISSN: 0864-4659 Vol. 48, No. 2, mayoagosto, pp. 23- 28. 